\title{
Measurement of HONO, HNCO, and other inorganic acids by negative-ion proton-transfer chemical-ionization mass spectrometry (NI-PT-CIMS): application to biomass burning emissions
}

\author{
J. M. Roberts ${ }^{1}$, P. Veres ${ }^{1, *}$, C. Warneke ${ }^{1, *}$, J. A. Neuman ${ }^{1, *}$, R. A. Washenfelder ${ }^{1, *}$, S. S. Brown ${ }^{1}$, M. Baasandorj ${ }^{1, *}$, \\ J. B. Burkholder ${ }^{1}$, I. R. Burling ${ }^{2}$, T. J. Johnson ${ }^{3}$, R. J. Yokelson ${ }^{2}$, and J. de Gouw ${ }^{1, *}$ \\ ${ }^{1}$ NOAA/ESRL, Chemical Sciences Division, R/CSD7, 325 Broadway, Boulder, Colorado, USA \\ ${ }^{2}$ University of Montana, Department of Chemistry, Missoula, MT, USA \\ ${ }^{3}$ Pacific Northwest National Laboratory (PNNL), Richland, WA, 99354, USA \\ *also at: CIRES, University of Colorado, Boulder, Colorado, USA
}

Received: 24 December 2009 - Published in Atmos. Meas. Tech. Discuss.: 28 January 2010

Revised: 5 July 2010 - Accepted: 12 July 2010 - Published: 23 July 2010

\begin{abstract}
A negative-ion proton-transfer chemical ionization mass spectrometric technique (NI-PT-CIMS), using acetate as the reagent ion, was applied to the measurement of volatile inorganic acids of atmospheric interest: hydrochloric $(\mathrm{HCl})$, nitrous $(\mathrm{HONO})$, nitric $\left(\mathrm{HNO}_{3}\right)$, and isocyanic (HNCO) acids. Gas phase calibrations through the sampling inlet showed the method to be intrinsically sensitive (6-16 cts/pptv), but prone to inlet effects for $\mathrm{HNO}_{3}$ and $\mathrm{HCl}$. The ion chemistry was found to be insensitive to water vapor concentrations, in agreement with previous studies of carboxylic acids. The inlet equilibration times for $\mathrm{HNCO}$ and $\mathrm{HONO}$ were 2 to $4 \mathrm{~s}$, allowing for measurement in biomass burning studies. Several potential interferences in $\mathrm{HONO}$ measurements were examined: decomposition of $\mathrm{HNO}_{3} \cdot \mathrm{NO}_{3}^{-}$clusters within the CIMS, and $\mathrm{NO}_{2}$-water production on inlet surfaces, and were quite minor $(\leq 1 \%, 3.3 \%$, respectively). The detection limits of the method were limited by the instrument backgrounds in the ion source and flow tube, and were estimated to range between 16 and $50 \mathrm{pptv}$ (parts per trillion by volume) for a $1 \mathrm{~min}$ average. The comparison of HONO measured by CIMS and by in situ FTIR showed good correlation and agreement to within $17 \%$. The method provided rapid and accurate measurements of $\mathrm{HNCO}$ and HONO in controlled biomass burning studies, in which both acids were seen to be important products.
\end{abstract}

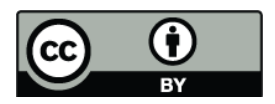

Correspondence to: J. M. Roberts (james.m.roberts@noaa.gov)

\section{Introduction}

The atmosphere is an oxidizing medium and, as such, it contains a number of acidic species. Many of the critical issues in atmospheric chemistry are related to the formation, transport, and deposition of key acidic species such as hydrochloric $(\mathrm{HCl})$, nitric $\left(\mathrm{HNO}_{3}\right)$, sulfuric $\left(\mathrm{H}_{2} \mathrm{SO}_{4}\right)$ and nitrous acids (HONO), as well as a number of organic acids (FinlaysonPitts and Pitts, 2000; Seinfeld and Pandis, 2006). Rapid and accurate measurements of these compounds are challenging, but nevertheless have been an essential part of understanding the detailed processes involving these species. The continued development and refinement of measurement methods is a valuable aspect of this research.

Methods for the measurement of gas phase atmospheric acids have progressed over the years from traditional bulk sampling with wet chemical analyses, requiring hours, to online spectroscopic techniques that can achieve second or subsecond time resolution. A general review of such analytical methods has been compiled by Clemitshaw (2004). Rapid ion-molecule reactions have recently been exploited in specific chemical ionization mass spectrometric (CIMS) methods for acids and related species (Huey, 2007; Crounse et al., 2006; Spanel et al., 1995; Custer et al., 2000; Hirokawa et al., 2009; Kim et al., 2008) that have been developed in recent years and involve ion chemistry that is selective and unique to the compounds of interest. Desirable features of CIMS methods are that they can be very sensitive and selective, and permit rapid $(<1 \mathrm{~s})$ measurements without requiring elaborate collection and separation steps. Some CIMS techniques have dependencies on other trace gases, particularly

Published by Copernicus Publications on behalf of the European Geosciences Union. 
water vapor, that interfere with and complicate the desired ion-molecule reactions (Huey et al., 1995; Crounse et al., 2006). The ease of producing an intense, relatively pure source of reagent ions is also a factor in the effectiveness of a CIMS technique for use in atmospheric measurements. In addition, atmospheric acids can be especially difficult to measure due to inlet surface effects (Neuman et al., 1999), which must be evaluated for losses, or degradation in time response.

The CIMS method used in this work has been described previously for carboxylic acids (Veres et al., 2008), and is based on the reaction of acetate ions, $\left\{\mathrm{CH}_{3} \mathrm{C}(\mathrm{O}) \mathrm{O}^{-}\right\}$, with acidic species via proton transfer, to produce acetic acid and the conjugate anion. The technique relies on the fact that acetic acid is among the weakest gas phase acids and will react by negative ion proton transfer (NI-PT) to abstract a proton from any species that is more acidic:

$$
\mathrm{HA}+\mathrm{CH}_{3} \mathrm{C}(\mathrm{O}) \mathrm{O}^{-} \rightarrow \mathrm{A}^{-}+\mathrm{CH}_{3} \mathrm{C}(\mathrm{O}) \mathrm{OH}
$$

Veres et al. (2008) showed that acetate ions could be produced efficiently and relatively cleanly via dissociative electron capture by acetic anhydride, using ${ }^{210} \mathrm{Po}$ as an ionization source. Moreover, there was no dependence of the ionization efficiency or reaction mechanism on water vapor concentration. This chemistry should also work for virtually all of the common inorganic acids, based on the gas-phase acidities (Bartmess, 2009) summarized in Table 1. Any acid with a gas-phase acidity value less than that of acetic acid will react spontaneously via Reaction (1).

Here we present results that show this NI-PT chemistry is an efficient and sensitive ionization method for the common gas phase acids $\mathrm{HCl}, \mathrm{HONO}, \mathrm{HNO}_{3}$ and isocyanic acid (HNCO). While HONO and HNCO are pyrolysis and combustion products of emerging interest, all four of these acid species present a challenge for atmospheric chemical analysis (Sipin et al., 2003). Calibrations and inlet tests were performed under varied water vapor concentrations in order to assess the response of the method to this important parameter. The system was used to measure acids emitted from burning biomass under laboratory conditions. The inlet system used for those measurements was tested for transmission/loss of species and the attendant equilibration time constants were measured. Possible interferences from secondary ion chemistry were estimated for high concentration conditions encountered in some experiments. The HONO measurements were compared with open-path FTIR measurements made at the same time.

\section{Experimental methods}

\subsection{NI-PT-CIMS instrument and calibration sources}

The NI-PT-CIMS instrument consists of an ion flow tube coupled to a quadrupole mass spectrometer and is shown in
Table 1. Gas phase acidities and anion masses of inorganic acids and compounds of potential interest.

\begin{tabular}{|c|c|c|c|}
\hline Compound & Formula & $\begin{array}{l}-\Delta G \\
(\mathrm{Kcal} / \mathrm{mole})^{\mathrm{a}}\end{array}$ & Anion Mass \\
\hline Perchloric Acid & $\mathrm{HClO}_{4}$ & 281 & 99,101 \\
\hline Sulfuric Acid & $\mathrm{H}_{2} \mathrm{SO}_{4}$ & $300^{\mathrm{b}}$ & 97 \\
\hline Hydroiodic Acid & $\mathrm{HI}$ & 309 & 127 \\
\hline Nitric Acid & $\mathrm{HNO}_{3}$ & 317.8 & 62 \\
\hline Hydrobromic Acid & $\mathrm{HBr}$ & 317.9 & 79,81 \\
\hline Phosphoric Acid & $\mathrm{H}_{3} \mathrm{PO}_{4}$ & $323^{b}$ & 97 \\
\hline Hydrochloric Acid & $\mathrm{HCl}$ & 328.2 & 35,37 \\
\hline Nitrous Acid & HONO & 333.7 & 46 \\
\hline Hydrogen Selenide & $\mathrm{H}_{2} \mathrm{Se}$ & $336.4^{\mathrm{b}}$ & $81^{\mathrm{c}}$ \\
\hline Isocyanic Acid & $\mathrm{HNCO}$ & 338.6 & 42 \\
\hline Hydroazoic Acid & $\mathrm{HN}_{3}$ & $338-339.8$ & 42 \\
\hline Acetic Acid & $\mathrm{CH}_{3} \mathrm{C}(\mathrm{O}) \mathrm{OH}$ & 341.5 & $59^{d}$ \\
\hline Hydrocyanic Acid & $\mathrm{HCN}$ & 343.8 & 26 \\
\hline Hydrogen Sulfide & $\mathrm{H}_{2} \mathrm{~S}$ & $345.6^{\mathrm{b}}$ & 33 \\
\hline Hypobromous Acid & $\mathrm{HOBr}$ & 347.1 & 95,97 \\
\hline Hypoiodous Acid & HOI & 347.4 & 144 \\
\hline Hypochlorous Acid & $\mathrm{HOCl}$ & 349.2 & 51 \\
\hline Hydrofluoric Acid & $\mathrm{HF}$ & 365.5 & 19 \\
\hline
\end{tabular}

${ }^{\text {a }}$ Gas phase acidity is defined as $-\Delta G$ for the process $\mathrm{H}^{+}+\mathrm{A}^{-} \rightarrow$ HA. Accordingly, the larger the value, the weaker the gas phase acidity of a given compound. Data are from the review by Bartmess (Bartmess, 2009).

b For the first proton.

${ }^{c}$ For the most abundant isotope.

$\mathrm{d}$ The reagent ion used in this work, included for reference.

Fig. 1. Details about the instrument can be found in previous publications (Slusher et al., 2004; Veres et al., 2008). The differences in the instrument as it was operated here were that a dilution system was constructed and the inlet was thermostatted at $80^{\circ} \mathrm{C}$ to reduce inlet absorption effects. The inlet was constructed of $1 / 8^{\prime \prime}$ o.d. Teflon PFA tubing and fittings, and was approximately $2 \mathrm{~m}$ in length, which allowed the instrument to be deployed on the top platform in the Fire Science Laboratory (McMeeking et al., 2009). The dilution in the inlet was adjusted to $35: 1$ for the experiments at the Fire Laboratory, and 8:1 for many of the calibration and inlet tests. The 0.46 standard liters per minute (slpm) flow into the ion flow tube was also reduced compared to the conditions used previously for carboxylic acids (Veres et al., 2008). Acetate ions were created by passing a mixture of acetic anhydride in nitrogen through a ${ }^{210}$ Po ionizer. The acetic anhydride source used in this work consisted of a small volume $\left(30 \mathrm{~cm}^{3}\right)$ bubbler through which a small flow of the source $\mathrm{N}_{2}(1.5 \mathrm{sccm})$ was directed. This gas stream was assumed to be saturated at the vapor pressure of acetic anhydride at the exit of the bubbler $\left(4\right.$ Torr at $25^{\circ} \mathrm{C}$ ), and that flow was combined with the total $\mathrm{N}_{2}$ flow $(2$ slpm) resulting in an estimated acetic anhydride mixing ratio of $4 \mathrm{ppm}$ in the flow stream as it passed through the ${ }^{210}$ Po ionizer. A $14 \mathrm{~cm}$-long ion flow tube at a pressure of 30 Torr was used throughout the experiments, resulting in a $0.24 \mathrm{~s}$ residence time in the ion-molecule reaction region. 


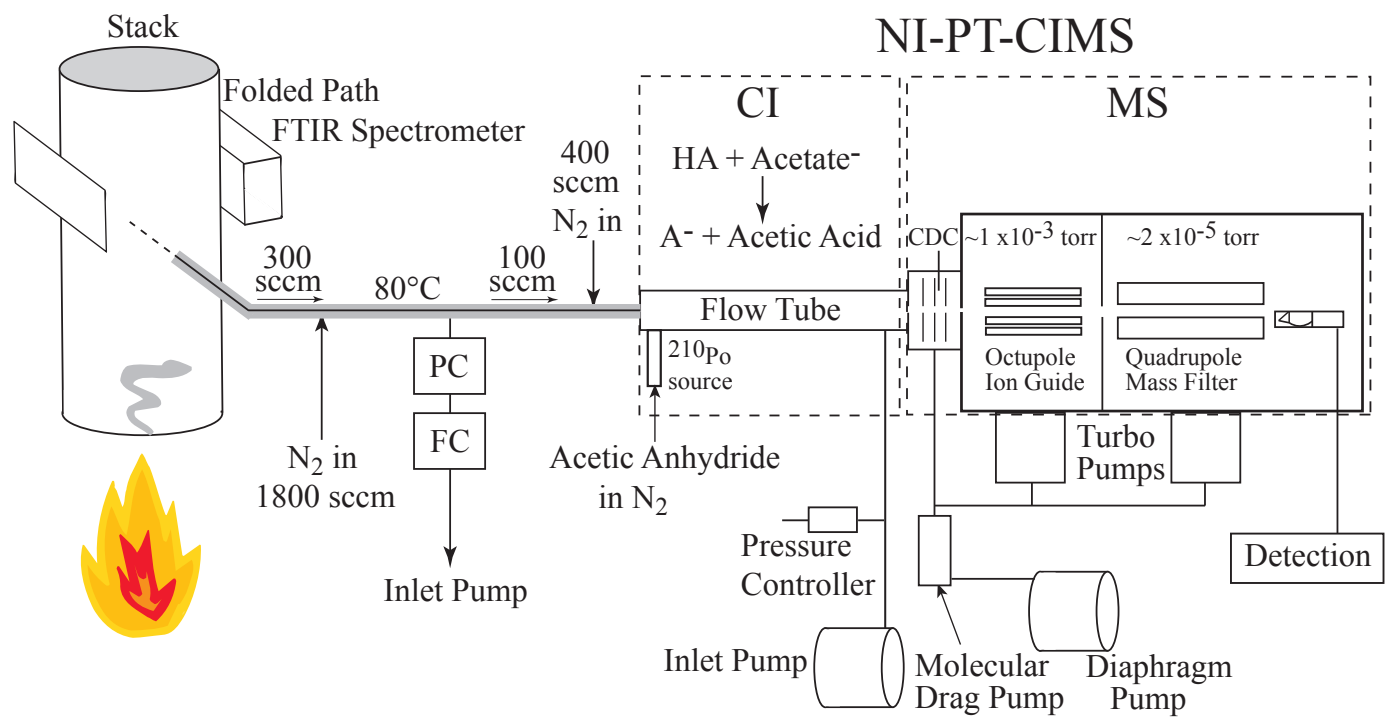

Fig. 1. Diagram (not to scale) of the NI-PT-CIMS and associated inlet system used for sampling the biomass burning experiments. The gray shading on the inlet line denotes the part that was thermo-stated at $80^{\circ} \mathrm{C}$.

Ions are sampled at the end of the flow tube through an orifice and analyzed by a quadrupole mass spectrometer. The data were acquired either by successive counting at a series of 10 masses for $0.500 \mathrm{~s}$ on each mass, or by mass scanning. Mass scans from 10 to $225 \mathrm{amu}$ were accomplished by increasing the mass setting by $0.20 \mathrm{amu}$ every $0.160 \mathrm{~s}$ and acquiring data for $0.150 \mathrm{~s}$.

The background ion counts for each channel during the fire laboratory experiments were determined from the signals measured in the stack before and after fires and were essentially the ion source and flow tube backgrounds with small contributions from the ambient air in the Fire Lab. Since these signals were comparatively small (several thousand counts) and stable on the timescale of the experiments (a few tens of minutes), this method of background subtraction did not add uncertainty to the measurements. In the laboratory studies below, a sodium carbonate $\left(\mathrm{Na}_{2} \mathrm{CO}_{3}\right)$-coated denuder tube, was used to remove the gas phase acids (>99\% efficiency) to provide an instrument "zero" for future ambient air measurements.

NI-PT-CIMS measurements of formic acid $\{\mathrm{HC}(\mathrm{O}) \mathrm{OH}\}$, $\mathrm{HNO}_{3}, \mathrm{HCl}, \mathrm{HONO}$, and $\mathrm{HNCO}$ were calibrated either by direct addition to the inlet as it was configured for the biomass burning experiments (Fig. 1), or after dilution in a 0-20 slpm pre-dilution system that was attached to the inlet when needed. A formic acid standard was added to the system to provide a baseline measure of instrument sensitivity throughout the biomass burning experiments and the subsequent laboratory studies of the inorganic acids. The formic acid source consisted of a thermostatted permeation tube that was routinely measured by catalytic conversion to $\mathrm{CO}_{2}$ and non-dispersive infrared spectroscopy (NDIR) (Veres et al., 2010a). Nitric acid was also added to the system with a permeation tube, the calibration of which was accomplished by UV absorption spectroscopy as described by Neuman et al. (2003). Hydrochloric acid was supplied to the system from a high-pressure gas standard (Spectra Gases), calibrated by the manufacturer at $10.1 \mathrm{ppmv}( \pm 5 \%)$. The standard was delivered to the inlet system through a regulator and mass flow controller that had been baked at $80^{\circ} \mathrm{C}$ and flushed with dry gas to remove surface-adsorbed water.

A standard stream of HONO was produced by passing the $\mathrm{HCl}$ standard through a bed of $\mathrm{NaNO}_{2}$, that had been humidified by a separate stream of air, and thermostatted to $40^{\circ} \mathrm{C}$ (Fig. 2a). This method was modeled on the work of Febo et al. (1995), and the work of Schiller et al. (2001) who showed that the carrier gas must be humidified or the $\mathrm{NaNO}_{2}$ dries out and the conversion efficiency drops. All of the components were made portable to permit the system to be transported between laboratories. The $\mathrm{NaNO}_{2}$ reactor bed consisted of approximately 2 grams of the granular material mixed with $3 \mathrm{~mm}$ glass beads (to ensure porosity) packed in an $8 \mathrm{~cm}$ long $\times 9.5 \mathrm{~mm}$ I.D. PFA Teflon tube. The reactor was wrapped with a heater and insulation and connected to the system with PFA fittings. The exit flow of the HONO source was in the range of $60 \mathrm{sccm}$ and contained HONO mixing ratios in the range of $900 \mathrm{ppbv}$, which was diluted into larger flows for analysis.

A thermal decomposition/diffusion source was constructed to provide a stable stream of HNCO in air (Fig. 2b). Thermal decomposition of solid cyanuric acid at $210^{\circ} \mathrm{C}$ provides a convenient and relatively clean source of $\mathrm{HNCO}$ (Belson and Strachan, 1982), which then diffuses through a capillary ( $1 \mathrm{~mm}$ i.d., $5 \mathrm{~cm}$ length) and is mixed with a small flow $(50 \mathrm{sccm})$ of zero air. The system was designed so that the entire capillary was kept at temperature and the gas 


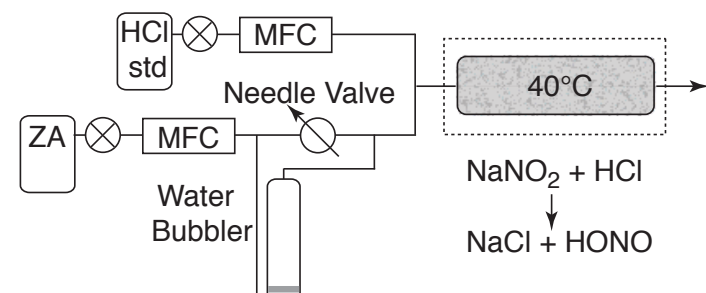

(a)

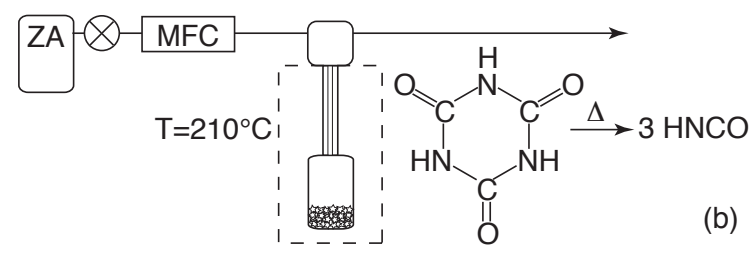

Fig. 2. Systems used to produce dilute streams of $\mathrm{HCl}$ and $\mathrm{HNO}_{2}(\mathbf{a})$, and $\mathrm{HNCO}$ (b) for the calibration of the NI-PT-CIMS instrument.

stream allowed to cool only after mixing to lower concentrations since $\mathrm{HNCO}$ is known to polymerize at high concentrations (Fischer et al., 2002). No condensed material was observed in, or downstream of, the mixing volume.

Several independent calibration methods were used for compounds generated as described above. Total oddnitrogen $\left(\mathrm{NO}_{\mathrm{y}}\right)$ was quantified by the catalytic conversion of $\mathrm{HONO}$ to nitric oxide (NO), which is measured by $\mathrm{O}_{3}$ chemiluminescence. The conversion efficiency of HONO has been found (Febo et al., 1995) to be the same as that of nitrogen dioxide, $(>98 \%)$, which is measured routinely as part of the operation of the $\mathrm{NO}_{\mathrm{y}}$ system. $\mathrm{HONO}$ and $\mathrm{NO}_{2}$ outputs from the calibration source were measured using an incoherent broadband cavity enhanced absorption spectrometer (IBBCEAS) (Washenfelder et al., 2009). IBBCEAS employs broadband light that is coupled into a high-finesse optical cavity to achieve a long effective pathlength, and has been used previously for measurements of HONO (Gherman et al., 2008; Langridge et al., 2009). The IBBCEAS instrument was modified for spectral measurements in the $357-372 \mathrm{~nm}$ region using a Nichia NCSU033A(T) UV LED and cavity mirrors (Advanced Thin Films) with manufacturer reported transmission of $0.0082 \%$ at their nominal center wavelength $362 \mathrm{~nm}$. A commercial laboratory FTIR spectrometer that has a $4.8-\mathrm{m}$ folded-path cell was used to analyze the $\mathrm{HNCO}$ source output, and was operated at room temperature $\left(25^{\circ} \mathrm{C}\right)$ and pressure (625 Torr).

\subsection{Fire sciences laboratory}

The biomass burning experiments were conducted at the Fire Sciences Laboratory of the US Forest Service in Missoula, Montana, according to standard protocols described previously (McMeeking et al., 2009). Water, elemental content $(\mathrm{C}, \mathrm{N})$, and weights of the fuels before and after burning were measured routinely. The fuels were chosen to reflect the varieties present on a number of Department of Defense (DoD) facilities in the western and eastern US. The details of fuel types are given elsewhere (Burling et al., 2010; Veres et al., 2010b).

The open path Fourier transform infrared (OP-FTIR) instrument consisted of a Bruker Matrix-M IR Cube spectrometer and an open path White cell whose end platters were thermally stabilized. The White cell was positioned on the sampling platform approximately $17 \mathrm{~m}$ above the fuel bed so that the horizontal infrared beam spanned the stack directly in the rising emissions stream. The reflected beam path length was set to $58 \mathrm{~m}$. The spectral resolution was set to $0.67 \mathrm{~cm}^{-1}$ and the spectrometer acquired spectra every $1.5 \mathrm{~s}$ (four co-added interferograms per spectra) beginning several minutes prior to the fire and continuously until the end of the fire. A pressure transducer and two temperature sensors were located adjacent to the optical path and were logged on the instrument computer; the temperature and pressure values were used for calculating the rotational-vibrational contours in fitting the measured spectra (Burling et al., 2010).

The IR spectra were analyzed offline with spectral fits for $\mathrm{CO}_{2}, \mathrm{CO}, \mathrm{H}_{2} \mathrm{O}, \mathrm{N}_{2} \mathrm{O}, \mathrm{NO}_{2}, \mathrm{NO}, \mathrm{HONO}, \mathrm{NH}_{3}, \mathrm{HCl}, \mathrm{SO}_{2}$, $\mathrm{CH}_{4}, \mathrm{CH}_{3} \mathrm{OH}$, HCHO, $\mathrm{HCOOH}, \mathrm{C}_{2} \mathrm{H}_{2}, \mathrm{C}_{2} \mathrm{H}_{4}, \mathrm{CH}_{3} \mathrm{COOH}$, $\mathrm{HCN}$, propene $\left(\mathrm{C}_{3} \mathrm{H}_{6}\right)$ and furan $\left(\mathrm{C}_{4} \mathrm{H}_{4} \mathrm{O}\right)$. Mixing ratios were obtained by multi-component fits to sections of the IR transmission spectrum using reference data from HITRAN (Rothman et al., 2009) and Pacific Northwest National Laboratory (Sharpe et al., 2004; Johnson et al., 2009, 2010) gas-phase databases. The algorithm was a synthetic calibration using a non-linear least-squares method (Griffith, 1996; Yokelson et al., 2007). Fire mixing ratios were calculated by subtraction of the 60 -s average mixing ratio prior to the ignition of the fire.

\section{Results and discussion}

\subsection{Mass spectrum}

Initial biomass burning NI-PT-CIMS measurements were performed with a low inlet flow and no dilution, but the system was too sensitive and required dilution because the high concentrations of acids depleted the reagent ion significantly. Dilution was accomplished using the flow scheme described above. Mass scans of both the diluted and undiluted sample stream were performed periodically to determine the presence and possible importance of acidic species. A scan of an undiluted sample is shown in Fig. 3, which shows prominent signals for $\mathrm{HNCO}$ and $\mathrm{HONO}$, a lower signal for $\mathrm{HCl}$, and a small signal for $\mathrm{HNO}_{3}$. Calibration and inlet tests for these inorganic acids are described below. 


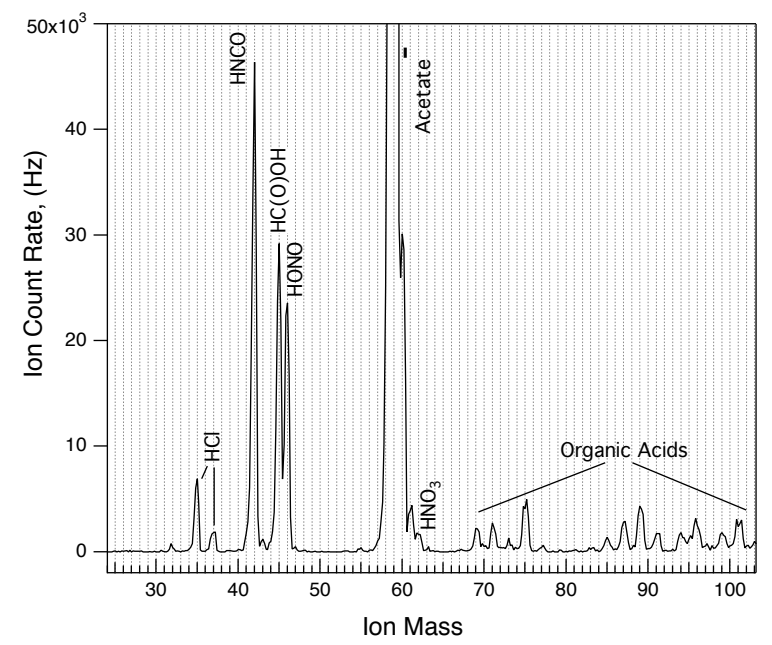

Fig. 3. A mass scan of Fire \#64, a sample of pine litter and duff from Fort Benning, GA, acquired with no dilution, beginning at $4 \mathrm{~min}$ after ignition. The spectrum was normalized so that the acetate ion signal was $10^{6}$ counts.

\subsection{Nitrous acid (HONO)}

The nitrous acid source was assembled as shown in Fig. 2a and was measured several times over the course of 10 days while the $\mathrm{HCl}$ standard and humidified air were flowing continuously. This time period was found to be essential for the proper equilibration of this source, probably because of the equilibration of $\mathrm{HCl}$ on the metal surfaces of the system. At the end of 10 days the $\mathrm{NO}_{\mathrm{y}}$, and IBBCEAS determination of the HONO standard were compared to the concentration expected from complete conversion of the $\mathrm{HCl}$ standard. The results, given in Table 2, show quantitative agreement of the measurements with the expected value, within the stated uncertainties. These observations confirm the work of Febo et al. (1995) wherein similar quantitative conversion was obtained. In addition, these results imply little or no production $(<4.5 \%)$ of ClNO as described by Perez et al. (2007) for a similar HCl-based HONO source.

The HONO source was added to the high flow dilution system and was sampled by the CIMS instrument as configured for biomass burning measurements. Dilution conditions were then adjusted to provide a range of HONO mixing ratios. The CIMS signal for $\mathrm{NO}_{2}^{-}$(mass 46) as a function of time is shown in Fig. 4a for one such experiment. The entire system equilibrated rapidly under both dry and humidified $\left(30 \% \mathrm{RH}\right.$ at $298^{\circ} \mathrm{K}$ ) conditions, as indicated by the time constant for decay of the HONO signal $(2.5 \mathrm{~s})$, when the source was removed from the system. This is an excellent time response considering the amount of surface area comprised by the inlet tubing and associated fittings. The sensitivity of the system to HONO was approximately $4 \mathrm{cts} / \mathrm{pptv}$ and was only slightly dependent on water vapor, as shown in Fig. 4b. The detection limits for a HONO measurement with this sys-
Table 2. Results of the HONO source calibration.

\begin{tabular}{ll}
\hline Source/Measurement & Mixing Ratio $( \pm 1 \sigma), \mathrm{ppbv}$ \\
\hline HCl Source & $904( \pm 90.4)^{*}$ \\
NO $_{\mathrm{y} \text { measurement }}$ & $885( \pm 53)$ \\
IBBCEAS & $863( \pm 86)$ \\
\hline
\end{tabular}

* Assuming 100\% conversion.
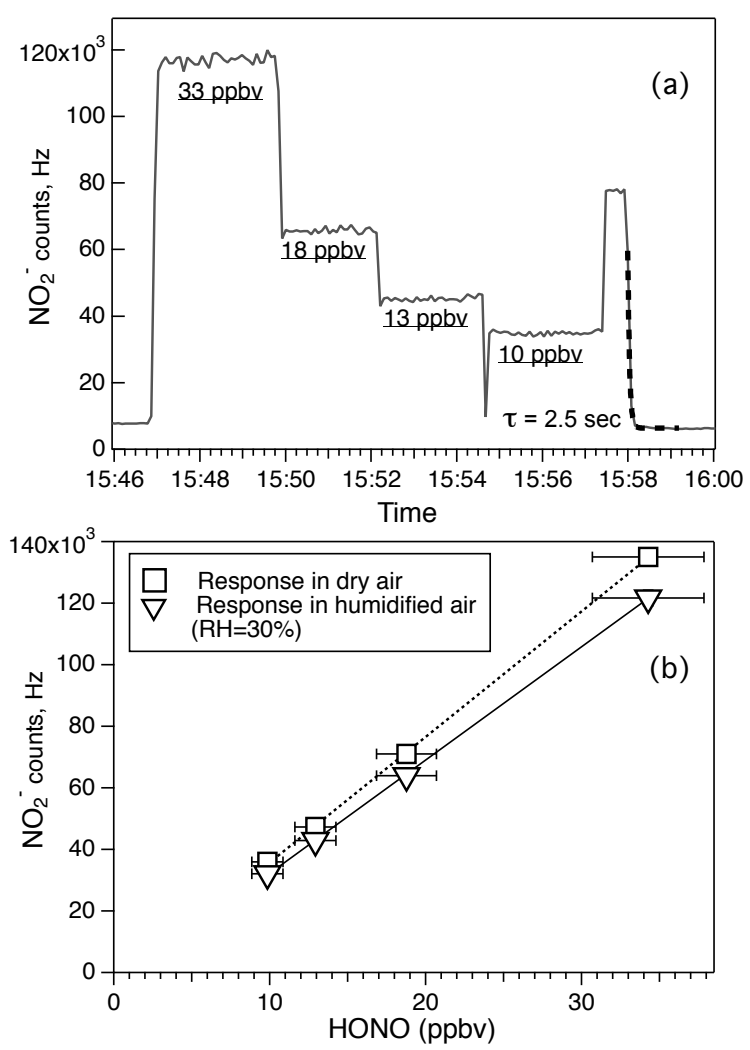

Fig. 4. The response of the NI-PT-CIMS to addition of the nitric acid standard directly before the ion flow tube. The nitric acid signal is shown in gray, the system response to removal of the nitric acid can be fit with a double exponential (dashed line). The signal in the nitrous acid channel (mass 46) is shown as open circles with the solid black line denoting the 60 -s average.

tem is dependent on the statistics of the background counts at mass 46 that arise from the inlet, ion source, and ion flow tube. The system as it was deployed in the biomass burning studies had an estimated detection limit of $200 \mathrm{pptv}(2 \sigma$, 1-s data). The system, as configured for ambient measurements, e.g. higher inlet flow, no dilution, has HONO sensitivities on the order of $10 \mathrm{cts} / \mathrm{pptv}$ and a corresponding detection limit of $35 \mathrm{pptv}(\mathrm{S} / \mathrm{N}=2,1 \mathrm{~min})$ assuming the mass 46 background is the same as that during the calibration studies $(\sim 6100 \mathrm{~Hz})$. These performance characteristics are summarized in Table 3. 
Table 3. Summary of sensitivities, detection limits and time constants.

\begin{tabular}{llll}
\hline Compound & $\begin{array}{l}\text { Sensitivity, } \\
\text { cts/pptv }^{\mathrm{a}}\end{array}$ & $\begin{array}{l}\text { Detection Limit, } \\
\text { pptv }^{\mathrm{b}}\end{array}$ & $\begin{array}{l}\text { Inlet Time Constant, } \\
\mathrm{s}\end{array}$ \\
\hline $\mathrm{HCl}$ & $2-4$ & 50 & $>90$ \\
$\mathrm{HNCO}$ & 16 & 16 & $\sim 2.5$ \\
$\mathrm{HONO}$ & 10 & 35 & 2.5 \\
$\mathrm{HNO}_{3}$ & $6^{\mathrm{c}}$ & 30 & $>480$ \\
\hline
\end{tabular}

a Sensitivity for an instrument configured for ambient measurements.

b Defined as $2 \sigma$ of the average of 1 min of the system background.

c Valid only for addition of the $\mathrm{HNO}_{3}$ source directly before the ion flow tube.

One source of interference for $\mathrm{HONO}$ could be nitrite produced from $\mathrm{HNO}_{3}$ or nitrate in the reaction flow tube. In previous studies using $\mathrm{HNO}_{3} \cdot \mathrm{NO}_{3}^{-}$clusters as reagent ions in the CIMS detection of sulfuric acid, Tanner et al. (1997) have shown that a small number of nitrite ions are produced from the collisional dissociation of those clusters. The possible contribution of this effect can be quantified in the current work from the $\mathrm{NO}_{2}^{-}$signal observed when $\mathrm{HNO}_{3}$ was added for calibration. Figure 5 shows a signal at mass 46 corresponding to approximately $1 \%$ of the added $\mathrm{HNO}_{3}$. The magnitude of this interference, while minor, might be reduced further through adjustment of the de-clustering conditions used in the collisional dissociation chamber (CDC).

Another known interference is production of HONO on surfaces exposed to $\mathrm{NO}_{2}$ and $\mathrm{H}_{2} \mathrm{O}$ (Sakamaki et al., 1983). This possibility was examined through the introduction of a gas-phase $\mathrm{NO}_{2}$ standard to the humidified inlet stream. In this case, a high concentration $\mathrm{NO}_{2}$ stream $(25 \mathrm{ppbv})$ produced a signal at mass 46 corresponding to $3.5 \%$ of what the same concentration of HONO would produce. The surface chemistry that governs this interference has been the subject of considerable research (Kleffmann and Wiesen, 2008 and references therein), and evidence suggests that the mechanism may be second-order in $\mathrm{NO}_{2}$ and that the amount and nature of inlet surfaces can have a large effect on the extent of HONO production. Application of our technique to ambient measurements will require careful consideration of these inlet issues.

\subsection{Isocyanic acid (HNCO)}

The large signal at mass 42 observed in the biomass burning study was initially a surprise (Fig. 3). Absent decomposition of a larger ion, which is unlikely using acetate as primary ions, some possible structures for this ion were $\mathrm{NCO}^{-}, \mathrm{CNO}^{-}$, or $\mathrm{N}_{3}^{-}$. The $\mathrm{CNO}^{-}$ion would result from fulminic acid $\mathrm{HCNO}$, and the $\mathrm{N}_{3}^{-}$ion from hydroazoic acid, both of which are highly unstable in both the gas-phase and condensed-phase (i.e. salts) and are therefore unlikely to be present. The $\mathrm{NCO}^{-}$ion could arise either from $\mathrm{HOCN}$, cyanic acid, or HNCO, (isocyanic acid). While cyanate salts, such as sodium cyanate $(\mathrm{NaOCN})$, are known to be stable,

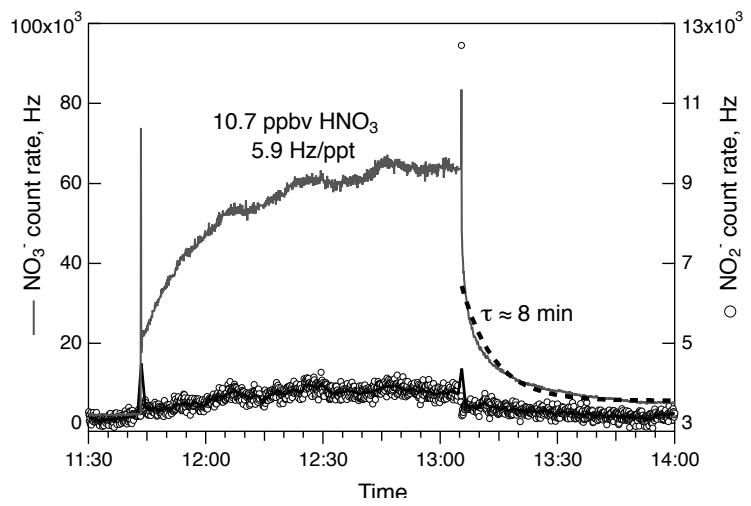

Fig. 5. Panel (a) shows the response of the NI-PT-CIMS to the HONO standard (gray line), introduced through the entire inlet. The simple exponential fit to the HONO signal when the standard was removed (dashed line) is also shown. Panel (b) shows the results of HONO calibrations under dry (squares) and 30\% humidity (triangles).

they evolve HNCO vapor upon acidification (Fischer et al., 2002), and HNCO has been shown to be the most thermodynamically stable of the possible CHNO isomers (Mladenovic and Lewerenz, 2008). There are several studies of the pyrolysis of biomass, coal, and polyamides, that have unambiguously identified $\mathrm{HNCO}$ as a major product by infrared spectroscopy (Hansson et al., 2004; Nelson et al., 1996). As a result of these studies and the above chemical considerations, the signal at mass 42 is assigned to HNCO.

The portable isocyanic acid calibration source stabilized within a few hours, based on the CIMS signal at mass 42 . The output of the source was then placed in the laboratory FTIR system and measured repeatedly until the spectra were constant. Figure 6 shows two consecutive spectra, taken 20 min apart, of the HNCO source stream in the 2050 $2400 \mathrm{~cm}^{-1}$ region. A reference spectrum from the Pacific Northwest National Laboratory (PNNL) infrared database (Sharpe et al., 2004; Johnson et al., 2009, 2010) is also shown. The FTIR spectra show that the source was stable within a few percent during the time it was analyzed. The source has substantial $\mathrm{CO}_{2}$ content $\left(2300-2400 \mathrm{~cm}^{-1}\right)$ probably from reaction with trace amounts of water, but virtually no carbon monoxide $\left(2200-2050 \mathrm{~cm}^{-1}\right)$, allowing quantitative measurement of the HNCO content by FTIR. The trace P-branch lines from naturally occurring ${ }^{13} \mathrm{CO}_{2}$ present a slight interference to analysis, but as seen in Fig. 6, quantitation is still possible. Several other methods were tried to quantify the output of this standard; the total carbon method (catalytic conversion to $\mathrm{CO}_{2}$ with measurement by NDIR), returned un-realistically high and variable signals due to $\mathrm{CO}_{2}$ coming out of the source. The $\mathrm{NO}_{\mathrm{y}}$ system exhibited almost no sensitivity to HNCO under the catalyst conditions used $\left(325^{\circ} \mathrm{C}\right.$, molybdenum oxide catalyst), consistent with the small conversion of hydrogen cyanide $(\mathrm{HCN})$ (Dickerson, 1984). 


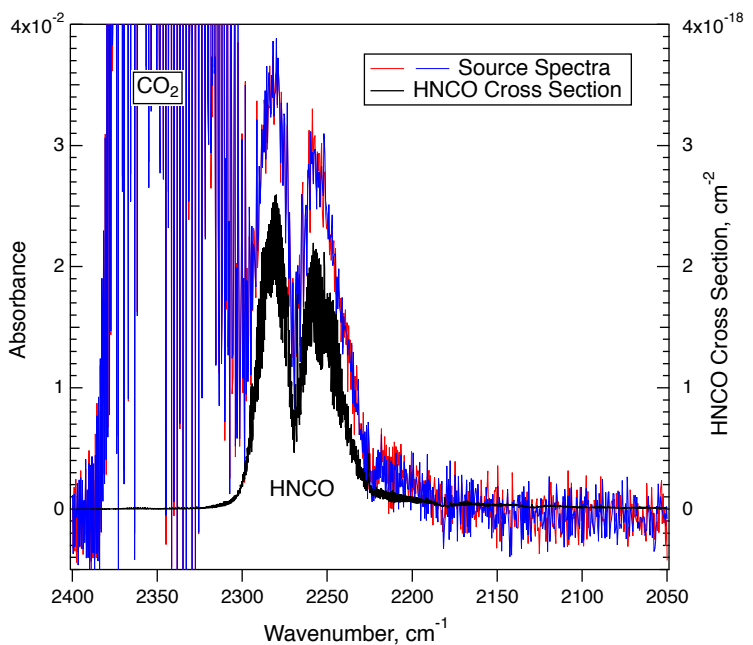

Fig. 6. Two consecutive Infrared spectra of the HNCO source output (red, blue) and the reference spectrum from the PNNL database (black).

The re-introduction of the HNCO source to the CIMS resulted in a signal that was within $3 \%$ of the signal before FTIR analysis, confirming the stability of the diffusion source. The HNCO concentration was then adjusted by changing the dilution of the high flow inlet. The CIMS response to a series of different concentrations is shown in Fig. 7a. The response was measured in dry air and the resulting calibration plot is shown in Fig. 7b. When the instrument is configured in the ambient measurements mode, the sensitivity of the system to HNCO was $16 \mathrm{~Hz} / \mathrm{pptv}$, greater than that for HONO or formic acid. There was only a small difference in the response to dry vs. humidified samples, indicating no significant role of water vapor in the underlying ion chemistry. Detection limit of the HNCO measurement as configured for ambient measurement would be $16 \mathrm{pptv}(\mathrm{S} / \mathrm{N}=2$, $1 \mathrm{~min})$ if the instrument background were the same as that during the calibration study $(\sim 3300 \mathrm{~Hz})$.

The time response of HNCO in the CIMS system can be characterized from the drop in the signal when the HNCO calibration is removed. Figure 7 a shows this decrease along with a fit to a double-exponential equation. In this case, most of the drop in signal was accounted for with a time constant of $2.3 \mathrm{~s}$. There was a longer "tail" in the signal that had a time constant of $48 \mathrm{~s}$. Both time constants are longer than the residence time of the inlet $(<0.5 \mathrm{~s})$. Nevertheless these surface effects play only a minor role in the case of $\mathrm{HNCO}$ and do not significantly affect the time constant of the measurement.

Measurements of HNCO have been limited to pyrolysis and combustion studies and some industrial hygiene studies in factories that work with isocyanate polymers. The methods include FTIR which is rapid and specific (Hansson et al., 2004), sample condensation and derivatization with a reagent containing an HO- or HNR- group (Karlsson et al., 2001),
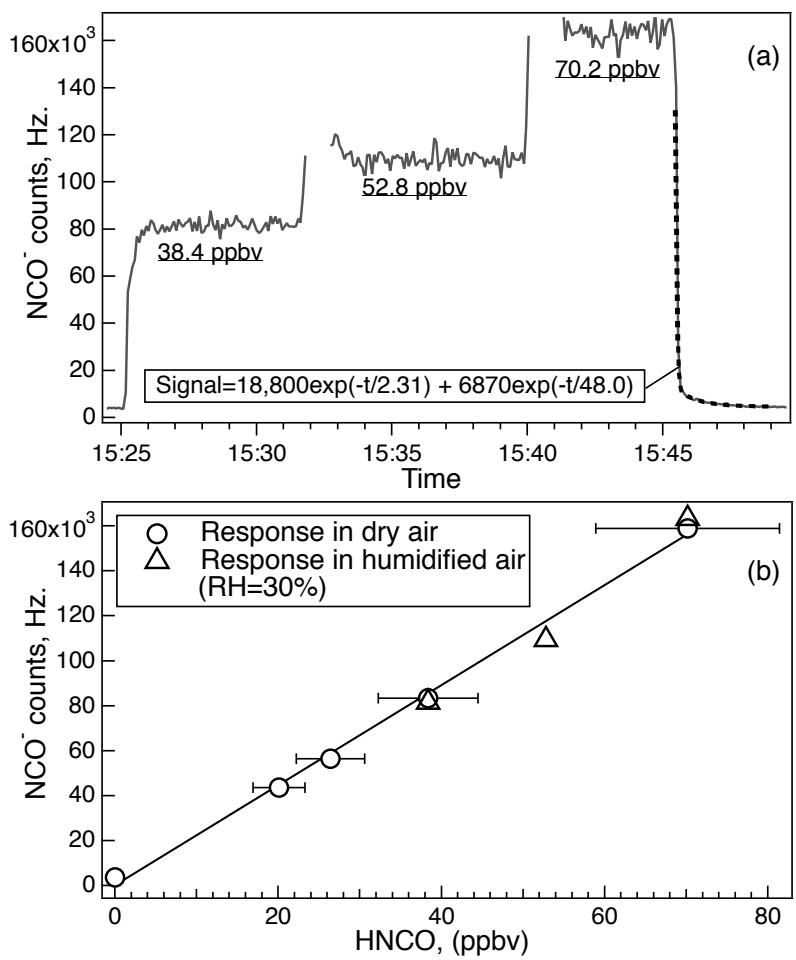

Fig. 7. Panel (a) shows the response of the NI-PT-CIMS to the HNCO standard (gray line), introduced through the entire inlet. A double exponential fit to the HNCO signal when the standard was removed (dashed line) is also shown. Panel (b) shows the results of HNCO calibrations under dry (circles) and 30\% humidity (triangles).

and selective hydrolysis and detection as $\mathrm{NH}_{3}$ (Krocher et al., 2005). All of these methods are limited either by low inherent sensitivity, or require significant sample collection times. The CIMS method presented in this work constitutes a significant advance in HNCO measurement capability and will provide rapid and sensitive ambient measurements of this compound.

\subsection{Hydrochloric and Nitric acids $\left(\mathrm{HCl}\right.$ and $\left.\mathrm{HNO}_{3}\right)$}

Several $\mathrm{HCl}$ and $\mathrm{HNO}_{3}$ calibration experiments were performed with both the diluted and un-diluted inlet, and with and without pre-dilution. Virtually no $\mathrm{HNO}_{3}$ signal could be detected when the standard was added to the front of the biomass burning inlet. Only addition of $\mathrm{HNO}_{3}$ directly in front of the ion flow tube produced a signal that equilibrated in a reasonable length of time (10 to $20 \mathrm{~min}$ ) (Fig. 5). These observations are qualitatively consistent with the results of Neuman et al. (1999) who showed that $\mathrm{HNO}_{3}$ adsorption on inlets can be substantial. The time constant for decay of the $\mathrm{HNO}_{3}$ signal when the $\mathrm{HNO}_{3}$ standard was removed from directly in front of the flow tube was approximately $8 \mathrm{~min}$. We conclude that while the method has intrinsically good 
sensitivity towards $\mathrm{HNO}_{3}$ (see Fig. 5), the inlet used did not permit measurement of this species in the biomass burning experiment.

Hydrochloric acid exhibited better behavior (measurable signals in any inlet configuration), however inlet equilibration times were still quite long (>90 s). Again, the intrinsic sensitivity of this method for $\mathrm{HCl}$ is good (2-4 cts/pptv), but the inlet configuration used in the fire experiment did not permit a quantitative measurement.

\subsection{Application of NI-PT-CIMS to biomass burning measurements}

Instrumental performance during the biomass burning studies are discussed here, with further description of the scientific conclusions from the biomass burning experiments will be presented elsewhere (Veres et al., 2010b; Burling et al., 2010). A timeline from one of the biomass burning experiments is shown in Fig. 8a for $\mathrm{HONO}, \mathrm{HNCO}, \mathrm{CO}_{2}$, and $\mathrm{CO}$. Two well recognized regimes are noted in this profile: (1) a flaming stage in which relatively efficient combustion produces mostly $\mathrm{CO}_{2}$ emissions, and (2) a smoldering stage in which the combustion is cooler and therefore relatively inefficient resulting in substantial $\mathrm{CO}$ emissions. The fastresponse CIMS measurement permits us to conclude that HONO is related to efficient combustion since it correlates quite closely with $\mathrm{CO}_{2}$ emissions. In contrast the $\mathrm{HNCO}$ emissions are most closely related to flaming stage $\mathrm{CO}$, as is shown in Fig. 8c where HNCO is correlated with $\mathrm{CO}$ measurements (interpolated to a 1-s timeline). The $\mathrm{HNCO} / \mathrm{CO}$ flaming stage slope is $0.28 \%$ in this experiment, and is likely related to the $\mathrm{C} / \mathrm{N}$ pyrolysis chemistry that takes place in biomass burning (Hansson et al., 2004).

The only compound that can be compared between the inorganic acids measured by the NI-PT-CIMS and the instack FTIR instrument is HONO. Figure $8 \mathrm{~b}$ shows that the comparison between the two measurements for this fire was very good, (slope CIMS:FTIR $=1.09, R^{2}=0.991$ ). Veres et al. (2010b) show that the over-all correlation between CIMS and FTIR HONO was good $\left(R^{2}=0.978\right)$ and there does appear to be a $17 \%$ bias in the CIMS measurement, but this is within the combined uncertainties of the two measurements. The CIMS data have not been corrected for $\mathrm{NO}_{2}$ and $\mathrm{HNO}_{3}$ interferences. Since the total $\mathrm{NO}_{\mathrm{x}}\left(\mathrm{NO}+\mathrm{NO}_{2}\right)$ values, were 6-10 times the HONO values, it is possible that some inlet production accounts for the slightly higher HONO observed by the CIMS.

\subsection{Application of NI-PT-CIMS to ambient air measurements}

The use of this method for ambient measurements of inorganic acids will benefit from reduction in instrument backgrounds and in understanding and controlling system interferences. System backgrounds seem to arise from two fac-
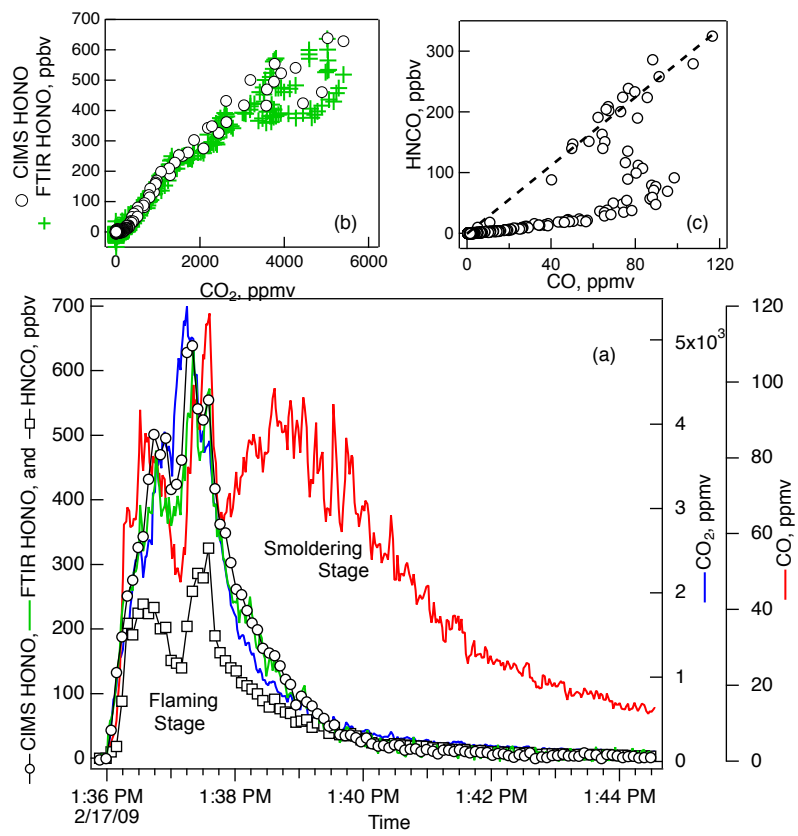

Fig. 8. A timeline (a) for the emission of: HONO measured by CIMS (open circles) and by FTIR (green line), HNCO (open squares), $\mathrm{CO}_{2}$ (blue line) and $\mathrm{CO}$ (red) during a biomass burning experiment. Also shown is (b) the correlation of both HONO measurements with $\mathrm{CO}_{2}$ and (c) the correlation of $\mathrm{HNCO}$ with $\mathrm{CO}$, showing the correlation with flaming-stage $\mathrm{CO}$ of $0.28 \%$ (dashed line).

tors; material adsorbed on the surfaces of the ion flow tube, and impurities in the ionization source. Heating the ion flow tube and ionizer slightly $\left(80^{\circ} \mathrm{C}\right)$ is suggested as a means to reduce surface adsorbed material. The addition of $\mathrm{NH}_{3}$ to CIMS systems to reduce backgrounds in $\mathrm{HNO}_{3}$ measurements, has been described by Huey et al. (1998) and Neuman et al. (2002), and was suggested as a solution to the high background of nitrate and perhaps other acid anions, since $\mathrm{NH}_{3}$ appears to react with surface-adsorbed nitric acid to prevent it from desorbing into the gas phase. However, preliminary work by one of our co-authors (J. A. Neuman, personal communication) with the $\mathrm{SiF}_{5}^{-}$CIMS, indicated that $\mathrm{NH}_{3}$ addition slows the response time to formic acid in that system. We interpret this to be a result of surface $\mathrm{NH}_{3}-\mathrm{HC}(\mathrm{O}) \mathrm{OH}$ complexes that are still partially volatile. A complete assessment of $\mathrm{NH}_{3}$ addition for the NI-PT-CIMS is beyond the scope of this paper and awaits further work. System backgrounds increased whenever the system was opened to room air to replenish the acetic anhydride sample, as required every few days in the above BB configuration. This problem can be eliminated through the use of a larger reservoir, or one that can be refilled without opening.

Interferences can be caused by ion decomposition or by unwanted neutral chemistry as described above for HONO and $\mathrm{HNO}_{3}$. The NI-PT chemistry produces simple conjugate 
anions, i.e. $\mathrm{HCl}$ produces $\mathrm{Cl}^{-}$, etc., which are often quite stable thermodynamically with respect to other ions, especially clusters. This amplifies the need for careful examination of species or processes that might interfere in ambient measurements.

\section{Conclusions}

The NI-PT-CIMS technique has been applied to the common volatile inorganic acids, $\mathrm{HCl}, \mathrm{HONO}$, and $\mathrm{HNO}_{3}$, and the pyrolysis product isocyanic acid (HNCO), and was found to provide a rapid and sensitive means for their measurement in the atmosphere. Intrinsic sensitivities to these species was quite good (6-16 ion cts/pptv) and the corresponding detection limits were reasonably low (16-50 pptv) compared to atmospheric levels. The detection limits were limited by system backgrounds at the ion of interest, hence are subject to improvements in ion source and flow tube cleanliness. The system, as configured for biomass burning experiments, had unacceptably long surface equilibration times for $\mathrm{HNO}_{3}$ and $\mathrm{HCl}$, but permitted rapid response $(<2.5 \mathrm{~s})$ to $\mathrm{HONO}$ and HNCO. Comparison of NI-PT-CIMS HONO measurements in the BB studies to those made by open path FTIR showed good correlation $\left(R^{2}=0.978\right)$ and an average positive bias of $17 \%$ for the NI-PT-CIMS measurement, which is within the combined uncertainties of the measurements. Application of this CIMS method to ambient measurements will require careful attention to inlet, zeroing, calibration and interference issues.

Acknowledgements. This work was supported by the NOAA's Health of the Atmosphere Program and NOAA's Climate Goal, NSF Grant No. ATM 1542457, the CIRES Innovative Research Program, and DoD SERDP Grant Nos. SI-1648 and SI-1649 in the sustainable infrastructure program.

Edited by: J. Stutz

\section{References}

Bartmess, J. E.: Negative ion energetics data, in: NIST Chemistry WebBook, NIST Standard Reference Database Number 69, edited by: Linstrom, P. J. and Mallard, W. G., National Institute of Standards and Technology, Gaithersburg, MD, 20899, 2009.

Belson, D. J. and Strachan, A. N.: Preparation and properties of isocyanic acid, Chem. Soc. Rev., 11, 41-56, 1982.

Burling, I. R., Yokelson, R. J., Griffith, D. W. T., Johnson, T. J., Veres, P., Roberts, J. M., Warneke, C., Urbanski, S. P., Reardon, J., Weise, D. R., Hao, W. M., and de Gouw, J.: Laboratory measurements of trace gas emissions from biomass burning of fuel types from the Southeastern and Southwestern United States, Atmos. Chem. Phys. Discuss., 10, 16425-16473, doi:10.5194/acpd-10-16425-2010, 2010.

Clemitshaw, K. C.: A review of instrumentation and measurement techniques for ground-based and airborne field studies of gas- phase tropospheric chemistry, Crit. Rev. Env. Sci. Tec., 34, 1108, 2004.

Crounse, J. D., McKinney, K. A., Kwan, A. J., and Wennberg, P. O.: Measurement of gas-phase hydroperoxides by chemical ionization mass spectrometry, Anal. Chem., 78, 6726-6732, 2006.

Custer, T. G., Kato, S., Fall, R., and Bierbaum, V. M.: Negative ion mass spectrometry and detection of carbonyls and $\mathrm{HCN}$ from clover, Geophys. Res. Lett., 27, 3849-3852, 2000.

Dickerson, R. R.: Measurements of reactive nitrogen compounds in the free troposphere, Atmos. Environ., 18, 2585-2593, 1984.

Febo, A., Perrino, C., Gherardi, M., and Sarapani, R.: Evaluation of a high-purity and high stability continuous generation system for nitrous acid, Environ. Sci. Technol., 29, 2390-2395, 1995.

Finlayson-Pitts, B. J. and Pitts, J. N. J.: Chemistry of the Upper and Lower Atmosphere, Academic Press, San Diego, 2000.

Fischer, G., Geith, J., Klapotke, T. M., and Krumm, B.: Synthesis, properties, and dimerization study of isocyanic acid, Z. Naturforsch., 57b, 19-24, 2002.

Gherman, T., Venables, D. S., Vaughn, S., Orphal, J., and Ruth, A. A.: Incoherent broadband cavity-enhanced absorption spectroscopy in the near-ultraviolet: Application to $\mathrm{HONO}$ and $\mathrm{NO}_{2}$, Environ. Sci. Technol., 42, 890-895, 2008.

Griffith, D. W. T.: Synthetic calibration and quantitative analysis of gas-phase FT-IR spectra, Appl. Spectr., 50, 59-70, 1996.

Hansson, K.-M., Samuelsson, J., Tullin, C., and Amand, L.-E.: Formation of $\mathrm{HNCO}, \mathrm{HCN}$, and $\mathrm{NH}_{3}$ from the pyrolysis of bark and nitrogen-containing model compounds, Combust. Flame, 137, 265-277, 2004.

Hirokawa, J., Kato, T., and Mafune, F.: In situ measurements of atmospheric nitrous acid by chemical ionization mass spectrometry using chloride ion transfer reactions, Anal. Chem., 81, 83808386, doi:10.1021/ac901117b, 2009.

Huey, L. G., Hanson, D. R., and Howard, C. J.: Reactions of $\mathrm{SF}_{6}^{-}$ and $\mathrm{I}^{-}$with atmospheric trace gases, J. Phys. Chem., 99, 50015008, 1995.

Huey, L. G., Dunlea, E. J., Lovejoy, E. R., Hanson, D. R., Norton, R. B., Fehsenfeld, F. C., and Howard, C. J.: Fast time response measurements of $\mathrm{HNO}_{3}$ in air with a chemical ionization mass spectrometer, J. Geophys. Res., 103, 3355-3360, 1998.

Huey, L. G.: Measurement of trace atmospheric species by chemical ionization mass spectrometry: speciation of reactive nitrogen and future directions, Mass Spectrom. Rev., 26, 166-184, 2007.

Johnson, T. J., Sams, R. L., Burton, S. D., and Blake, T. A.: Absolute integrated intensities of vapor-phase hydrogen peroxide $\left(\mathrm{H}_{2} \mathrm{O}_{2}\right)$ in the mid-infrared at atmospheric pressure, Anal. Bioanal. Chem., 95, 377-386, 2009.

Johnson, T. J., Profeta, L. T. M., Sams, R. L., Griffith, D. W. T., and Yokelson, R. J.: An infrared spectral database for detection of gases emitted by biomass burning, Vib. Spectrosc., 53, 97-102, 2010.

Karlsson, D., Dalene, M., Skarping, G., and Marand, A.: Determination of isocyanic acid in air, J. Environ. Monit., 3, 432-436, 2001.

Kim, S., Huey, L. G., Stickel, R. E., Pierce, R. B., Chen, G., Avery, M. A., Dibb, J. E., Diskin, G. S., Sachse, G. W., McNaughton, C. S., Clarke, A. D., Anderson, B. E., and Blake, D. R.: Airborne measurements of $\mathrm{HCl}$ from the marine boundary layer to the lower stratosphere over the North Pacific Ocean during INTEX-B, Atmos. Chem. Phys. Discuss., 8, 3563-3595, 
doi:10.5194/acpd-8-3563-2008, 2008.

Kleffmann, J. and Wiesen, P.: Technical Note: Quantification of interferences of wet chemical HONO LOPAP measurements under simulated polar conditions, Atmos. Chem. Phys., 8, 6813-6822, doi:10.5194/acp-8-6813-2008, 2008.

Krocher, O., Elsener, M., and Koebel, M.: An ammonia and isocyanic acid measuring method for soot containing exhaust gases, Analyt. Chem. Acta, 573, 393-400, 2005.

Langridge, J. M., Gustafsson, R. J., Griffith, P. T., Cox, R. A., Lambert, R. M., and Jones, R. L.: Solar driven nitrous acid formation on building material surfaces containing titanium dioxide: A concern for air quality in urban areas?, Atmos. Environ., 43, 5128-5131, 2009.

McMeeking, G. R., Kreidenweis, S. M., Baker, S., Carrico, C. M., Chow, J. C., Collett Jr., J. L., Hao, W. M., Holden, A. S., Kirchstetter, T. W., Malm, W. C., Moosmuller, H., Sullivan, A. P., and Wold, C. E.: Emissions of trace gases and aerosols during the open combustion of biomass in the laboratory, J. Geophys. Res., 114, D19210, doi:10.1029/2009JD011836, 2009.

Mladenovic, M. and Lewerenz, M.: Equilibrium structure and energetics of CHNO isomers: Steps towards ab initio rovibrational spectra of quasi-linear molecules, Chem. Phys., 343, 129-140, 2008.

Nelson, P. F., Li, C.-Z., and Ledesma, E.: Formation of HNCO from the rapid pyrolysis of coals, Energy and Fuels, 10, 264 265,1996

Neuman, J. A., Huey, L. G., Ryerson, T. B., and Fahey, D. W.: Study of inlet materials for sampling atmospheric nitric acid, Environ. Sci. Technol., 33, 1133-1136, 1999.

Neuman, J. A., Huey, L. G., Dissly, R. W., Fehsenfeld, F. C., Flocke, F., Holecek, J. C., Holloway, J. S., Hubler, G., Jakoubek, R., Nicks, D. K., Parrish, D. D., Ryerson, T. B., Sueper, D. T., and Weinheimer, A. J.: Fast-response airborne in situ measurements of $\mathrm{HNO}_{3}$ during the Texas 2000 Air Quality Study, J. Geophys. Res., 107, 4436, doi:10.1029/2001JD001437, 2002.

Neuman, J. A., Ryerson, T. B., Huey, L. G., Jakoubek, R., Nowak, J. B., Simons, C., and Fehsenfeld, F. C.: Calibration and evaluation of nitric acid and ammonia permeation tubes by UV optical absorption, Envir. Sci. Tech., 37, 2975-2981, 2003.

Perez, I. M., Wooldridge, P. J., and Cohen, R. C.: Laboratory evaluation of a novel thermal dissociation chemiluminescence method for in situ detection of nitrous acid, Atmos. Environ., 41, 39934001, 2007.

Rothman, L. S., Jacquemart, D., Barbe, A., Benner, D. C., Birk, M., Brown, L. R., Carleer, M. R., Chackerian, C., Chance, K., Coudert, L. H., Dana, V., Devi, V. M., Flaud, J. M., Gamache, R. R., Goldman, A., Hartmann, J. M., Jucks, K. W., Maki, A. G., Mandin, J. Y., Massie, S. T., Orphal, J., Perrin, A., Rinsland, C. P., Smith, M. A. H., Tennyson, J., Tolchenov, R. N., Toth, R. A., Vander Auwera, J., Varanasi, P., and Wagner, G.: The HITRAN 2008 molecular spectroscopic database, J. Quant. Spectrosc. Radiat. Transf., 110, 533-572, 2009.
Sakamaki, F., Hatakeyama, S., and Akimoto, H.: Formation of nitrous acid and nitric oxide in the heterogeneous dark reaction of nitrogen dioxide and water vapor in a smog chamber, Int. J. Chem. Kinet., 15, 1013-1029, 1983.

Schiller, C. L., Locquiao, S., Johnson, T. J., and Harris, G. W.: Atmospheric measurements of HONO by tunable diode laser absorption spectroscopy, J. Atmos. Chem., 40, 275-293, 2001.

Seinfeld, J. H. and Pandis, S. N.: Atmospheric Chemistry and Physics: From Air Pollution to Climate Change, 2nd Edn., John Wiley and Sons, New York, 2006.

Sharpe, S. W., Johnson, T. J., Sams, R.L., Chu, P.M., Rhoderick, G.C., and Johnson, P. A.: Gas-phase databases for quantitative infrared spectroscopy, Appl. Spectrosc., 58, 1452-1459, 2004.

Sipin, M. F., Guazotti, S. A., and Prather, K. A.: Recent advances and some remaining challenges in analytical chemistry of the atmosphere, Anal. Chem., 75, 2929-2940, 2003.

Slusher, D. L., Huey, L. G., Tanner, D. J., Flocke, F. M., and Roberts, J. M.: A thermal dissociation-chemical ionization mass spectrometry (TD-CIMS) technique for the simultaneous measurement of peroxyacyl nitrates and dinitrogen pentoxide, J. Geophys. Res., 109, D19315, doi:19310.11029/12004JD004670, 2004.

Spanel, P., Pavlik, M., and Smith, D.: Reactions of $\mathrm{H}_{3} \mathrm{O}^{+}$and $\mathrm{OH}^{-}$ with some organic molecules; applications to trace gas analysis in air, Int. J. Mass Spectrom. Ion Proc., 145, 177-186, 1995.

Tanner, D. J., Jefferson, A., and Eisele, F. L.: Selected ion chemical ionization mass spectrometric measurement of $\mathrm{OH}, \mathrm{J}$. Geophys. Res.-Atmos., 102, 6415-6425, 1997.

Veres, P., Roberts, J. M., Warneke, C., Welsh-Bon, D., Zahniser, M., Herndon, S., Fall, R., and de Gouw, J.: Development of negativeion proton-transfer chemical-ionization mass spectrometry (NIPT-CIMS) for the measurement of gas-phase organic acids in the atmosphere, Int. J. Mass Spectrom., 274, 48-55, 2008.

Veres, P., Gilman, J. B., Roberts, J. M., Kuster, W. C., Warneke, C., Burling, I. R., and de Gouw, J.: Development and validation of a portable gas phase standard generation and calibration system for volatile organic compounds, Atmos. Meas. Tech., 3, 683691, doi:10.5194/amt-3-683-2010, 2010a.

Veres, P., Roberts, J. M., Warneke, C., de Gouw, J., Burling, I. R., and Yokelson, R. J.: Measurements of gas-phase inorganic and organic acids in biomass fires by negative-ion proton-transfer chemical-ionization mass spectrometry (NI-PT-CIMS), J. Geophys. Res., doi:10.1029/2010JD014033R, submitted, 2010b.

Washenfelder, R. A., Langford, A. O., Fuchs, H., and Brown, S. S.: Measurement of glyoxal using an incoherent broadband cavity enhanced absorption spectrometer, Atmos. Chem. Phys., 8, 7779-7793, doi:10.5194/acp-8-7779-2008, 2008

Yokelson, R. J., Karl, T., Artaxo, P., Blake, D. R., Christian, T. J., Griffith, D. W. T., Guenther, A., and Hao, W. M.: The Tropical Forest and Fire Emissions Experiment: overview and airborne fire emission factor measurements, Atmos. Chem. Phys., 7, 5175-5196, doi:10.5194/acp-7-5175-2007, 2007. 